\title{
言
}

Niels Ole Finnemann

\section{Digitization: new trajectories of mediatization?}

\author{
"Media matter to practices of communication \\ because embodiment matters." \\ (J. D. Peters 1999: 65)
}

\begin{abstract}
The purpose of this chapter is to clarify what the concept of digital media might add to the understanding of mediatization and what the concept of mediatization might add to the understanding of digital media.

It is argued that digital media open an array of new trajectories in human communication, which were not anticipated in previous conceptualizations of media and mediatization. If digital media are to be included, the concept of mediatization has to be revised and new parameters must be integrated in the concept of media. At the same time, it is argued that the concept of mediatization still provides a variety of perspectives of relevance to the study of digital media.

The claim that the concept of mediatization has to be reinterpreted can only be legitimized if digital media are considered distinct from the media formerly referred to in mediatization theory. Such characteristics are presented and digital media are defined in section 2, while section 1 is devoted to theories of mediatization and the notion of media. Section 3 analyses the relation between mediatization and digitization. Finally, in section 4, medium theory is revisited with a view to harvest some missing fruits in contemporary mediatization theory.
\end{abstract}

Keywords: digital materials and genres, digitization and mediatization, grammar of digital media, institutionalization of media, Internet and mass media, materializations of media, media theories: modern or general, medium theory, modes of mediatization, notion of networked digital media

\section{Theories of mediatization}

For years processes of digitization have represented a major trend in the developments of modern society, but they have only recently been related to processes of mediatization.

Among the unresolved questions in recent discussions on the concept of mediatization are the following questions: When did mediatization emerge? Which media are taken into account? How do different media add to the concept? How are the relationship between the time/space properties, the material characteristics of various media, and the institutional forms understood? 
Some answers to the first question refer exclusively to "contemporary media" (Strömbäck 2008; Hjarvard 2008); others refer to all sorts of communication throughout history (Rothenbuhler 2009). The most dominant idea, however, is to see mediatization on a par with processes of individualization, modernization, and globalization, which are closely connected to modern media, print, radio, film and television, and digital media (Krotz 2007; Lundby 2009; overview in Finnemann 2011; Hepp 2013). Except for Rothenbuhler (2009), focus is exclusively on modern media or what Altheide and Snow (1979: 11) called modern “overshadowing” media.

The second question, about which media are taken into account, refers back to the first question of emergence. But the question of "which media" is not simply a matter of historical origin and the particular long-term perspective referred to; it is also a matter of which communicative activities within a given society are included. Thus, it remains unsettled whether the concept includes the overall set of media within a given society (Rothenbuhler 2009), a selected set (Hjarvard 2008), whether it relates to a specific medium (Strömbäck 2008) or it refers primarily to an evolutionary logic in the incorporation of new media whenever they emerge (Schulz 2004).

The third question, about what different media add to the concept, is more complicated. According to Krotz (2007), mediatization is a metaprocess that does not depend on particular media. Mediatization is everywhere, at least in modern societies. On the other hand, mediatization can only exist in particular practices, as there is no general logic of media. However, it also seems that mediatization has a kind of history that unfolds itself somehow, though the agencies in these processes are seldom made explicit. Others have argued that the concept is closely connected to specific institutional forms, which also add a sort of historical agency, an ability to impose a particular logic, and agenda-setting capacities (Hjarvard 2008; Strömbäck 2008).

The fourth question - How is the relationship between the time/space properties, the material characteristics of various media, and the institutional forms understood? - seems to be the most difficult; there have been quite a lot of indications that the materiality of media does not matter at all, but very few attempts to provide an answer. It appears that all sorts of media technologies - writing systems, the printing press, the telephone, television systems, the Internet - are simply reduced to "technology", which can be left out of the analysis of media cultures. Hepp builds on a distinction between "first order media", such as "the internet as a vehicle for the transmission protocol/internet protocol (TCP/IP) model", and "second order media", which "are in addition social cultural institutions of communication” (2013: 4). In this case, media technology, for instance TCP/IP Internet protocols, does not seem to be part of a social cultural institution of communication. This is a surprise. Media and communication studies are based on these "technical media", the properties of which it will exclude in a theory of 
mediatization. Since digital media introduce a radical change in the materialization of media, this blind spot will be further discussed below.

To include digital media, the concept of mediatization will in the following be used as a metaconcept, referring to the basic characteristics of human communication: it is always mediated, but in a variety of historically distinct forms. Consequently, mediatization cannot be said to comprise a general set of properties characterizing all sorts of mediated communication or a family of properties distributed in different ways among the members. Instead the concept will be used to denote main parameters for analysing particular mediatization processes related to particular media in particular constellations of media.

Any such constellation of media which is available in a society is denoted as a matrix of media. The particular institutionalizations are denoted as media systems. The matrix may be the same, even if usages and institutionalizations differ in say different countries, as shown in Hallin and Mancini (2004) for print news media. Mediatization processes will always refer to both dimensions. The matrix, the set of available media, specifies the material repertoire as well as the time and space constraints of communication, but it does not reveal how the repertoire is institutionalized and used in a given society. Thus, agencies and institutionalizations are not part of the matrix, but of the media systems that comprise the whole chain of communication within a society, including all communicating agencies (Finnemann 2011).

Usages come into question in both dimensions. On the one hand, usages are constrained and facilitated by the properties of the available media in the matrix. On the other hand, the selected utilizations also depend on the interplay between the economic, institutional, political, social, and cultural needs of the citizens.

The metaconcept is derived from Krotz, but in a more generalized interpretation, embracing the whole history of human communication. This is in accordance with the claim that all forms of human communication are externalized, materialized and encoded in a shared social system (Peters 1999; Rothenbuhler 2009: 287). Thus, mediatization is not exclusively related to modern media, even if they add a series of new trajectories for communication.

In this there are two hard pills for modern media theory to swallow. First, writing and speech are both considered media. Since its emergence in the 1970s and 1980s, the discipline of media and communication studies has defined itself in opposition to a narrow concept of text as written or printed. While print is sometimes included, writing is seldom acknowledged as a medium. It seems that "the media" come into play only when "mechanical devices" detached from the human body are involved in the reproduction process. This is the modernist bias of media theory. The second pill is perhaps even harder to swallow, as speech is most often considered a conceptual antipode defining "non-media". Speech is seen as opposed to externalized, tangible media and is often also associated with authenticity and intimate privacy. Here media theory is in accordance with a more widespread ignorance in modern thinking. 
In a recent discussion of the genesis of the media concept, Guillory stated that a notion of "media" for modern communication technologies appears only in the late $19^{\text {th }}$ century "as a response to the proliferation of new technical media - such as the telegraph and phonograph - that could not be assimilated to the older system of the arts" (Guillory 2010: 321). He also argued that modern thinking did not make room for a notion of media, even if it did often stumble into the need, referring, among other things, to Ferdinand Saussure's interpretation of writing as subordinate to speech, while ignoring other media in his theory of language. One cannot but think of Plato and Descartes' distinctions between the ideal world of forms, res cogitans, both outside the constraints of time and space, and the material world, res extens $a$, which only exists in time and space. Since media are material vehicles for ideas, they belong to both spaces or to a third space in between; the existence of such a space is excluded in these dualisms.

To capture the field excluded by Cartesian dualism, one may need to redefine the concept of a medium, which in the following will be used for any sort of organized physical material used for some symbolic purpose, i.e. for communication. This is comparable to a classic definition given, for instance, by Altheide and Snow, according to whom a medium is "any social and technological procedure or device that is used for the selection, transmission, and reception of information" (1979: 11). Even if this is a wide definition which explicitly includes calendars, fashion, and dance as media, it completely excludes the material properties of media.

Whether the physical material takes the more fluid form of energy or the more fixed form of matter is important for the understanding of the distinct properties of different media, but it makes no difference for the fundamental definition. Both energy and matter are physical, and if organized for communicational purposes and intentions, this organization is what turns physical material into media. Media are always in between, mediating between matter and mind as well as between humans and between humans and our imaginations, experiences, and ideas of the world. The triple nature of this definition can be clarified by the distinction between three types of noise derived from Shannon's mathematical theory of information, though he did not explicitly identify all three forms (Shannon and Weawer [1949] 1969). The first form is trivial physical noise disturbing communication, as the physical forms used for communication are more or less drowned by, for instance, background noise or other sources. The second form is semantic noise, which occurs when the message is not properly understood due to coding discrepancies between the sender and the receiver, when they do not use the same codes for interpreting the physical forms as mediated signs. The third form is media noise in the form of the occurrence of a physical form that is legitimate form in a given coding system, say an alphabet, but not meant to be part of the actual communication. Shannon found the third type particularly interesting, and his solution was to increase the redundancy in the messages transmitted (Finnemann [1994] 1999a: 156-196). 
There are two main reasons for leaving the platonic and the modernist bias behind.

First, speech and writing that predate modern mass media have never been fully replaced, while their functions and usages have changed relative to the inclusion of new media in the matrix. The histories of all societies include a history of rostrums for speaking in public - be it thing steads, thrones, pulpits, cathedrae, courts, chairs, lecterns, Hyde Park corner, or wherever people might gather around a speaker. Such floors where speakers can speak to somebody in front of them are institutionalized parts of the media systems in all known societies. Around the formalized thrones and chairs there is always also a sphere for more or less informal and often less public spoken negotiations.

Second, when it comes to digitization, there is no exclusive limit between media and non-media. Speech, writing, radio, as well as television can be made subject to digitization. Such digital reproductions can be combined deliberately. This is possible, because they are already mediated, speech included, although in different physical forms. Digitization implies that non-digital originals are converted into a shared physical format - the binary alphabet - that can be mechanically processed bit by bit, simply because the bits are defined as physical units. The question of whether it is possible to limit mediatization to not include speech and writing and only embrace some digital media and not all of them will be further discussed below.

Since the history of media is characterized by the recurrent advent of new media, it follows that processes of mediatization take on new forms and properties. These processes take place neither as an additive aggregation of forms, nor as a mere increase in the number of different types of media, but as major reconfigurations of the relations between media on the level of institutionalization as well as on the level of the matrix. In this respect, the point of departure is Wolfgang Riepl's theory of media evolution (Riepl 1913), modernized, among others, by Meyrowitz (1985), Schulz (2004), Krotz (2007, 2009) and Finnemann (1999b, 2011).

According to Riepl, new media seldom or never fully replace old media. More often they initiate functional changes. If so, new media lead to the establishment of a new general matrix of media that is more complex, both because the array of media is widened and because old media are often developed and used for new purposes and functions. The introduction of new media implies that a new layer is incorporated in the communicational infrastructure. The invention of writing induced a more complex matrix of media and led to a variety of new media systems, ranging from the systems found in Greek city states to the systems found in Chinese, Roman, and other empires and medieval European principalities. Without writing there would be no state, no general law, and no clear distinction between past and present. In Europe the take-up of print based on movable types in the $15^{\text {th }}$ century also brought new layers to the matrix, as did the invention of radio and television in the more globalized and US-dominated world of the $20^{\text {th }}$ century. 
Since evolutionary theory is often described as linear and deterministic or not applicable to cultural phenomena, three things should be noted.

First, no determinism is necessary, as there is no reason to claim, for instance, that writing caused the development of state, law, and the writing of history. Writing is merely a necessary precondition for these developments, and they, of course, have to be explained in a broader analysis of the dynamics of the societies in question.

Second, some of the most interesting aspects of evolutionary processes are precisely their nonlinear nature, manifested in the principle of refunctionalization identified by Riepl and others. In modern evolutionary biology the notion of exaptation has been proposed, focusing on the non-deterministic increase in complexity. The concept of exaptation was introduced in Gould and Vrba (1982) as "the process by which features acquire functions for which they were not originally adapted or selected" (Oxford English Dictionary). Among the examples, Gould (1991) mentions the development of human speech: a most vital medium of human communication. For a critical discussion see Buss et al. (1998).

Third, attempts to stress a fundamental ontological distinction between natural processes of evolution and cultural processes make sense only in a Cartesian, dualistic interpretation of bodies living in a biomaterial world (as part of res extensa) and human minds living in a distinct mental world (res cogitans). As said, Cartesian dualism did not allow for any sort of medium in between the two realms.

It has been argued (Hepp 2013: 51), with reference to Norbert Elias (1991), that there is a difference between the "instrument of transmission and change" in biological evolution, which is driven by genes, and sociocultural development, which is driven by symbols.

If there is a difference, it cannot be a difference between two completely separate spheres. It has to be a distinction in the very same biological or biosemiotic universe. Biology as a science may not include culture and, thus, still reserve itself to a reductionist stance, but human communication is necessarily embodied and mediated in between living organisms. The mind operates in the very same time and space as the brain and both are incorporated in the body of a living organism. In the following it is assumed that all media always mediate between physical, biological, and mental dimensions. This is possible only because they are materially organized to fulfil some sort of symbolic articulation.

Epistemologically this implies a move from the psychophysical parallelism of the $20^{\text {th }}$ century (information theories, game theory, structuralism, etc.) to noncausal psychophysical interactionism. Today we can safely assume that mental processes are materially processed in the neurophysiological system; res cogitans is intertwined with res extensa. The brain is a medium of the mind; mental states may change physical states and vice versa. Reductionist theories deny such characteristics, as they do not allow individual events that are not rule-governed. However, if all individual events were determined by previous events, there would be 
no language and no meaning. If all parts of a linguistic sentence were causally determined by rules, it would not be possible to express any unique message in that language.

This is the point of departure for the anchoring of the media concept in between biophysical and symbolic processes, which again is a precondition for anchoring the concept within human communication. Media become part of human epistemology, as they both limit and allow communication. What we can know about the universe depends on the available media for observation and communication. Contemporary ideas of the universe, including theories of the Big Bang and black holes, are based on indices provided by mediated recordings of digitized signals from outer space, thus making our worldview conditioned by the capacities of digital observation media. The worldviews of today could not exist without digital media. Even if this notion of media goes well beyond the usual perspectives of media and communication studies, there are no safe arguments for a more restricted conceptualization.

The main parameters for all known kinds of human communication relate to time, space, material form, and institutional form. It is argued that following these four parameters all media may be characterized as unique relative to each other. For any medium, additional parameters, for instance perceptual and semiotic parameters, may come into question, but all sorts of human communication can be characterized according to these four parameters, cf. Finnemann (2011).

The space, time, and material characteristics of media relate to technologies that - even if they are societal constructs and thus variables - are also transcendent to the particular social context in which they are constructed or used. This is why they can be identified as media. Face-to-face communication is the only form of communication, if any, in which the communicating partners can be in almost the same situation. But only almost in the same situation. If nothing else, language will always extend beyond the situation. The same is the case for memory, which also connects the individual to extra-situational experiences. Thus, all media, speech included, somehow transcend the situation in respect to time and/or space.

The relevance of mediatization theory relates both to an understanding of the general characteristics of a given constellation of media and to the characteristics of changes in the set of available media and media institutions within a society. It may also be included in the analysis of the relation between media epochs and wider issues of historical epochs. Finally, mediatization theory in this form makes it possible to predict a range of new trajectories opened by the advent of new media as a result of the identification of ways in which they may be used to change the overall matrix, including time, space, material, and institutional aspects of human communication.

The concept of mediatization is not applicable on the micro level of the single act of communication, as it refers to general features, which are transcendent to any particular communication act. No such singular act provides sufficient infor- 
mation to reveal whether it is part of established routines, belongs to any specific cultural context, or eventually becomes part of a new trajectory. These questions can only be answered if one adopts perspectives which transcend the situation. The world cannot be conceived of as consisting of associated situations and localized contexts only or as an infinite array of mediatized worlds separated from each other. The global reach of the Internet does not imply a global village, but it does imply that any situation can easily be extended globally by any citizen. Today, we have synchronous face-to-face communication and textualized near-synchronous communication across any distance on earth, and you can never know if you end up on YouTube tonight.

However, in the case of digital media, the issue is not simply a matter of the number of particular characteristics of new media. It is a matter of conceptualization of both mediatization and of digital media.

\section{The concepts of digitization and digital media}

Digital media emerge as materials of stored content, as a repertoire of methods for search, analysis, and presentation, and as media for communication. Digital media always convey some sort of digital material, and they are always also search engines which provide a repertoire of possible methods for analysing and presenting in a perceptible form otherwise invisible, stored digital materials. If they are interconnected, they may also serve as a means for communication in all spheres of society.

These three basic dimensions of material, method, and media are intertwined and their interrelations are variable. As a consequence, the utilization of one of these dimensions will also affect the two other dimensions, but since the relations are variable, this is not a predetermined relationship.

Each of the three dimensions provides a register of new opportunities for human communication and together they open up for a far-reaching reconfiguration of the communicational infrastructures in human history - insofar as some of the new opportunities are selected and utilized to meet certain needs and desires.

In the following, a few unique characteristics of each of these three dimensions will be presented briefly to indicate a profile of the disruptive potentials of digital media in the history of media.

\subsection{Digital materials}

Digital materials are manifested in the binary alphabet. This is their only shared characteristic. The hidden algorithmic structures and the semantic representations on the level of the interface may vary. Thus, digital materials differ from each 
other, because they are somehow marked according to their provenances, what they are about, how they are produced and used, and in what sorts of formats. This is where culture and politics sneak into the very roots of digital media in still new ways.

Brügger and Finnemann (2013) distinguish between digitized materials and "born" digital materials. The former includes all analogue materials that have been digitized, as is the case with a growing range of cultural heritage materials, such as digitized print materials, newspapers, radio programmes, and television programmes. Digitized materials are reproductions of non-digital originals. Depending on the source, the reproduction is subject to some sort of distortion or noise. A linguistic text coded in the Latin alphabet may be reproduced in its entirety. The digitized reproduction of the material qualities of the paper will be noisy. A tiny grain on the paper may look like a punctual mark, i.e. noise type three. Digitized reproductions of non-digital sounds and images will also be noisy due to the binary coding of colours varying on a continuous scale, as is well-known. Nevertheless, digitization of non-digital materials gives rise to a range of new opportunities for the use, further reproduction and distribution and, not least, the study of these materials, due to the characteristics described below in sections 2.2, 2.3 and 2.4 .

Born digital materials, of course, come without such distortions. They also differ from digitized materials because digital materials may include hypertextual and interactive features as original features, whereas such features can only be non-original additions to digitized materials.

Digitized materials exist in a digital format, which is defined a posteriori to the original format. Born digital materials can both be created in their own digital format and recreated in different formats; the latter is, for instance, the case with archived web materials, which constitute one of the most complex sets of data materials.

Digital materials also include a huge variety of forms which are seldom included in media and communication studies. This is the case for geo-located online information, which is now frequently utilized even in the online editions of mass media. We also find a growing variety of digital materials distributed via mobile devices in public - sometimes interactive - spaces, such as cities and other networked spaces, making these spaces communicational spaces not formerly considered mediatized. Digital media are used for surveillance of people's behaviour in public as well as private spaces. This is both performed by separate surveillance media and by utilizing the huge amounts of information "given off" by people travelling the net. Service providers increasingly create so-called "data doubles" of the people using the services.

People also produce an increasing number of digital self-representations, such as personal profiles on a variety of digital platforms. While some are private profiles, created for use in connection with home banking or online health services, 
others are anonymous and semi-anonymous usernames used in various debate and chat forums, online gaming sites, quasi 3D universes, etc., and finally others are public personal profiles, such as those used on Facebook, LinkedIn, and similar services. The range of such "avatars" widens over the years, thus reflecting changing age, personal preferences, tastes and interests, identities, and social belonging.

The universe of digital materials goes even further as it also includes the use of digital circuits in mechanical devices, be it traffic lights, cars, washing machines, dishwashers, refrigerators, ovens, watches, printing presses, electronic measuring instruments, robots, or alarms; the Internet of things; more sensitive utilizations such as electronic tags on prisoners, children, and senile people; circuits incorporated in pacemakers or operated into the body to replace ruined nerve fibres and connecting patients and hospitals for monitoring and adjustment purposes; observational data from scanning our interior parts, including the brain; and creating data from outer space, which all together allow us to reconsider the structure of the universe as well as our ways of thinking and creating meaning in and of the world.

Thus, the question is raised whether it is possible to limit the concept of mediatization to include only some of these digital materials and methods and ignore others. Of course, this question also concerns the very notion of media and the delimitation of the object proper of media and communication studies.

These questions cannot be safely answered without looking at the dimensions of search and communication.

\subsection{Digital methods for search and representation}

Digital materials can only be accessed by means of digitally supported search and retrieval methods to establish the re-presentation of the invisible, stored content on a screen or another output device. This relation is not conceivable in phenomenological interpretations of media communication, but it is a part of all forms of digital media and a fundamental part of the contemporary processes of mediatization, if digital media should be included.

Any digital device includes a digital search engine, as it is the mechanism used to set in motion any sequence of bits processed in the machine, whether a mainframe, a PC, a laptop, a web server, a mobile device, a pedometer, a scanner, or other. Even without recognizing it as such, the mobile devices people carry in their pockets today work as search engines. People feel uncomfortable without it. The search engine inherent in all digital devices opens a new trajectory in human communication as the basis for a fast growing amount of digital search procedures, also accompanied by the development of software-supported methods for analysing digital materials. 
Search is an old activity, but mechanical search is rather new. Mechanical search by means of punch cards was developed before the advent of modern digital computers. Also radio receivers were early on capable of detecting radio stations based on wavelength. But the rich semiotic potentials of digital search were only slowly and gradually acknowledged, until Google short-circuited the classic search paradigms in the late 1990s (Halavais 2009).

The cultural role of digital search for digital materials, search engines, and the ever-growing array of search methods and paradigms takes digital media beyond formerly known media. Insofar as contemporary culture is increasingly articulated in digital forms, it follows that the methods used to find, use, and study these matters will increasingly have to exploit digital search methods. None of this applies to any formerly known machines or media.

The new methodological perspectives go beyond the scope of this article, but an example may give an indication. Survey methods are well-established. Web surveys constitute an emerging field. The conditions of validity differ from former survey methods, and a whole range of new options are to be explored, as it is now possible to utilize the hypertextual, interactive, and multimodal repertoires in combination with scalable reach according to the local/global and time scale. Thus, it is possible to develop interview strategies which combine quantitative and qualitative questions, to use answers given to ask new questions, to stretch the time scale, to establish dialogic relations between interviewers and respondents, or to include references to materials from the web. The array of new methods also includes, among others, website analysis, web-sphere analysis (Foot and Schneider 2006), and a range of link- and big data analyses.

This does not mean that older methods should necessarily be dismissed. They may still be useful and incorporated in the composition of multi-layered methodologies developed as a response to the increasing complexity of the media systems and the overall matrix. However, without utilizing software-supported methods there will be significant and growing lacunae in what we do know in media and communication studies.

All media convey materials, but in different formats, allowing different kinds of operations and all media may serve as means of communication in one or several respects, but most do not include a methodological component, either for search or for making the materials visible. Digital search engines represent one of the most fundamental and unique innovations provided by digital media and form the basis for major changes in the role of media in a society and, thus, in the history of media.

\subsection{Digital communication institutionalized}

"New media" studies tend to consider "new media" the sole media in history and often also ignore the history of digital media and the transformations of the media systems. Thus, one might look to mediatization theory to bridge the gaps. 
However, even if mediatization theory includes institutionalization, changes in the media systems due to the utilization of digital media and the new, more complex matrix are seldom addressed. Even Schulz, who describes a set of evolutionary features, concludes in the end "that new media are not actually that new" (2004: 97), though he did not analyse the new media system. Recent interpretations tend to give up the idea of the existence of a media system. Dahlgren and Alvares (2012) claim that the distinctions between old and new media are eroding, but they leave the erosion process itself out of sight. This is strange, as almost all mass media have been striving hard to reinvent themselves in recent years, offline and online (Küng, Picard and Towse 2008).

According to Schulz (2004), the media system comprises economic, technological, and semiotic dimensions. Digital media are used as game changers in all three dimensions.

In the development from stand-alone computers to networked digital media these media have changed from being mainly instrumental for the mass media to being a new field for their activities. In the late $20^{\text {th }}$ century, the mass media had gained editorial control over public communication. With the Internet, their position as gatekeepers to the public had weakened. Direct access to the public for everybody was primarily provided via the web protocols published on the Internet in 1991. The open Internet allowed a much more varied set of editorial criteria to be practised. Individual citizens, communities, professional expert systems as well as all kinds of political, cultural, and social agencies were now able to bypass the mass media and communicate directly to the public. With the American decision in 1993 to open the Internet for commercial activities (Boucher's Bill) new commercial enterprises entered into the business field of mass media, providing news, background information, opinion building processes, and entertainment. For a wider public the value of the Internet was made clear in the wake of the 9/11 terror bombing in New York during the burst of the IT bubble in 2001, as the Internet turned out to be superior to other means of communication for governmental institutions, companies involved, relatives, and other concerned people around the globe.

In the early $21^{\text {st }}$ century a new business model emerged. It was centred on the search engine, providing a set of search facilities for free, while financing the activities by relating ads to the inputs of users. The basic model could be applied on any scale from local to global and for any sort of activity. Within few years, however, a small group of new global players (such as Google, Facebook, Amazon, Apple, YouTube) became dominant. Each of these services was used by a wider audience than any of the mass media and they took over a large part of the revenues in the media industries. The new players, thus, became a threat to the mass media, due to economy, due to their scalable reach, ranging from local to global, due to the scalable variation of public, semi-public and private communication and, more generally, due to their better understanding of the new modes of com- 
munication and search made possible by the Internet. The media systems experienced still ongoing structural changes on a global scale (Castells 2009).

In the same process the mass media tried to digitize themselves and enter the networked digital platforms. They changed from being anchored primarily in a particular media technology (print or electronic) to becoming multi-platform media corporations (Wurff and Laub 2005). Their role as gatekeepers for access to the public and for maintaining the distinction between what should - and what should not - be considered of public relevance with respect to moral and quality standards has weakened, but they still hold an important role in public opinion building in many countries. To perform this role, however, they have had to establish themselves on the Internet and they are increasingly dependent on the wider array of public voices articulated elsewhere on the Internet.

A most important feature underlying this process is the speed and global reach of digital communication, as it allows for near-synchronous communication between people and all sorts of digital archives on a global scale, be it news archives, health services, image archives, or any other sort of information or news service. This is why concepts like interoperability between different kinds of digital resources have grown into prominence in the IT strategies of today, for instance in the world of libraries as well as in the US and EU research infrastructure initiatives and elsewhere. There is no reason to rely on the idea that these developments will remain irrelevant to the mass media. On the contrary, if mass media do not adjust to keep pace, they will be "googled" once again, as they were "googled" with the launch of Google ads in the early $21^{\text {st }}$ century. Networked digital media have also made possible the development of a range of new short, written formats, ranging from email, chat, messaging, texting, blog entries to comments, status updates, and tweets (Baron 2008). Thus, personal near-synchronous and asynchronous typewriting is included in the range of public media.

The speed of electronic media is a precondition. But so is the storage capacity. While writing and print media are storage media which may be distributed, analogue electronic media are primarily media of high-speed communication. The related storage media, if any, are usually separate, such as the gramophone record, the film roll, the (video) tape of the tape recorder. The seamless integration of the speed of electronic communication and the storage capacities of print media in one digital device forms the basis for a growing variety of digital genres in between and beyond previously existing genres, whether spoken, written, printed, or electronic. Finally, it also makes everything digital searchable. In this respect too electronic digital media differ radically from analogue electronic media. Analogue electronic media are also gradually digitized, which means that properties of digital media are gradually built into formerly analogue media. Teletext can be seen as an early and popular example, predating the short formats mentioned above, but utilizing only a limited set of digital features. The existence of intermediary forms in between analogue and digital media does not reduce the significance of the 
differences. On the contrary, it documents that analogue electronic media cannot fulfil contemporary needs for communication.

The integration of storage and high-speed communication in globalized networks changes the conditions of media and communication studies. It affects the fundamentals, not simply of the objects and the people who use the media, but of scholarship and media and communication studies as a discipline, including theories, methods, and materials (Reips 2008), allowing shortcuts in the academic knowledge production chain (Finnemann 2013).

\subsection{Digital media defined}

Compared to former media materials, digital materials differ in a number of respects, some of which become evident when comparing analogue materials with their digitized equivalents. For instance, a printed text can only be "manually" searched, while a digitized version of the text can be searched mechanically for any particular sequence. To this comes the range of hypertextual, interactive, and multimodal facilities of contemporary digital media, which have only rudimentary forerunners in the printed world. For images the difference is even more fundamental, since the digital representation implies that even still images, formerly existing and understood as units independent of space and time, in their digital form become a product of serial processes performed in time, even if they are still perceived as still images. This is also the case for television, but digitization implies textualization of the image with respect to editability. In the extreme, each pixel in a digital image can be ascribed and edited in keeping with its own distinct timeline. There is no final limit for the editability of digital images. Any single image can be converted into any other possible digital image. While all images may be digitized, there is no way back from a digital version to the analogue original. Instead, we have an indefinite repertoire of possible printouts of new instances of any sort of digital material, limited only by the question of whether it makes sense for somebody. Digital media do not imply the end of print, but rather the end of out of print.

Digital materials cannot be handled without the use of digital methods for storing, searching, combining, analysing, and presenting. They may, in some respects, still be analysed using well-known methods, but since a fast growing number of social, cultural, and political activities are articulated in digital forms and performed via digital platforms, it follows that the development of digital methods, both in society at large and in research, will have a still more significant role to play. Thus, media and communication studies are confronted with a medium which trespasses the boundaries between the object and the methodological devices and architectures for studying the object, which at the same time has become a moving target. 
The variability of the relations between digital materials, methods, and modes of communication makes these media more open for projections of different ideas than any formerly known device. They come with a variable functional architecture, both on the level of the devices and, even more so, on the software level. The relation between fixed hardware and modifiable software is itself variable. It may, in many cases, be convenient to dedicate a device to a limited set of purposes by integrating a greater part of the functional architecture in the hardware. This is why the explosive growth of software formats and genres goes hand in hand with an explosive growth of dedicated devices and gadgets, ranging from mainframes and PCs to mobile devices and microchips, which may be implemented in everything and everywhere. The functional architecture can be modified according to any set of ideas, needs, and desires. Digital media can be made responsive to the content of individual messages. Thus, they allow us to produce growing amounts of still more different kinds of digital materials and digital devices, which may be tailored to almost any convenient physical form and are mainly restricted by the human need for interfaces to make sense of binary processes.

In Brügger and Finnemann (2013) we argue that the ongoing development of new types of digital materials combined with the variability of the functional architecture as well as the growing number of dedicated devices calls for a reinterpretation of the computer. Thus, "digital media" is used to denote not simply the networked connections between many computers, but also to replace 1) the concept of uniform digital datasets with the notion of heterogeneous digital materials, 2) the idea of computation as a uniform (mathematical, logical, rule-governed) process with the conceptualization of digital processes such as search, storage, and representation, supported by hypertextual, interactive, and multimodal means, and 3) the idea of the computer as a programmed machine performing the same limited set of repetitive or iterative operations (and the equivalent idea of IT as a given constant) with the idea that digital media have a variable functional architecture.

This definition of digital media deviates, on the one hand, from the concept of the computer as a rule-governed machine, which originally developed in connection with the interpretation of the mainframe machines of the 1950s and 1960s. On the other hand, it deviates from the Human-Computer Interaction (HCI) conceptualization of a digital toolbox interpreting the personal computers of the 1980s, and which paved the way for the spread of computers from the specialized fields of IT experts into society at large. Both of these definitions were based on stand-alone computers. The definition of digital media, however, also deviates from the widespread "new media" concept (or the implicit assumption) of the computer as a plastic and freely malleable device that comes with no built-in constraints. The definition will be further unfolded in section 5 by drawing on main insights from medium theory.

This prehistory of the concept is still important, not simply because previous conceptualizations are still around, but also because the prehistory reveals that 
digital media enter into the history of media from the outside and were only very recently recognized as media, both by the mass media and the media scholars. During the 1980s and 1990s the literature on IT came predominantly from other areas than media and communication studies.

\section{Digitization meets mediatization}

The processes of mediatization meet digitization processes in two ways.

First, since the 1970s digitization has taken place from within in many particular parts of the media institutions, mainly as a substitute for a particular function like typesetting or bookkeeping, without wider implications for the function of the media in society. Today most processes in the production, technical reproduction, administration, and communication of media are digitized. In principle, the mass media could have been fully digitized without affecting their functioning in society significantly. However, the very same processes also open up for quite different developments as a result of social and cultural needs and desires and changes in the conceptualization of digital media and the whole range of new facilities they provide (Finnemann 2014).

Second, digitization processes came to the mass media from the outside. Even if the mass media started digitization processes in the 1970s, they did not become a main agency in the innovative usages of digital media, which took place in the same years, leading to the Internet, and were later followed by a growing array of dedicated digital devices, some of which are mobile devices. The mass media were absent from the development of the international digital networks and, thus, more or less absent in the first fifty years of digital media.

Mediatization theory has followed the mass media and did not confront itself with processes of digitization and the spread of digital media before they became disruptive in the history of mass media in the early $21^{\text {st }}$ century. As a consequence of this, a main issue for mediatization theory is to specify the criteria for inclusion of digital media in the conceptual framework. Is it possible, for instance, to delimit only the processes which relate to the mass media? Or should the concept be extended to include all sorts of digitization processes?

Conceptually, mediatization comes off as a broader concept than digitization, as it includes references to a number of non-digital media. On the other hand, it is still unclear whether it should include all kinds of digital processes, as described above. If mediatization does not include all sorts of digital processes, where the limit should be drawn will become a constant issue.

A most familiar suggestion would be to include only digitization processes in the sphere of mass media. These are usually limited to television, radio, and printed newspapers. Today such an approach would have to include some parts of the Internet, such as the websites of mass media, their Facebook sites, and 
other external forums under the editorial supervision of established media. It fails, however, as news production and news distribution and public opinion building also take place in numerous places elsewhere on the net. Mass media are not the only agencies that can now publish on a $24 / 7$ basis. This is also the case for politicians, lobbyist groups, any sort of expert system, and every citizen. Why should their contributions not be included? Even Google cannot keep track of this new universe of news, while the mass media are left further behind, because they are unable to include the long tails of diversified news and information of relevance to people. According to a survey on media usage in Denmark in 2009, television was still the most widespread medium, while print media and radio fell behind the Internet. Most people also used Google and Facebook, but even more people also used a number of specialized websites, each of which may only have been used by relatively few (Finnemann et al. 2012). The Internet is fit to serve such long tail patterns, which are increasingly important due to the exponential growth in knowledge and news production and entertainment.

Some critics might suggest that an editorial quality criterion could form a basis for deciding what counts as media, thus refraining from including all digital media as such. It would be easy, however, to identify numerous websites which outdo a majority of existing mass media with regard to quality of information.

A wider approach might include all sorts of public spaces on the Internet, including blogs, debate and chat forums, some parts of Facebook, Twitter, YouTube, some mailing lists, commercial as well as civic sites addressing issues of common interest. Such an approach also fails, because the very distinction between private and public - and semi-public - spaces on the net is not decided by "the media", but by individuals and groups who may change their priorities from situation to situation, making some information public one day and private the next due to changing perspectives and motives.

The concept of media is most often used for articulations manifested in externalized communication media. A third distinction, therefore, might be related to externalization. Digital processes are only included if they are manifested in externalized, tangible devices, which can be handed over between people. This would equal a distinction between "unmediated" speech and mediated writing, as the product of writing can be handed over to others, whereas speech cannot. However, wireless communication between a pacemaker and a hospital, scanning internal bodily states, brain states for instance, can easily be made part of public communication, because externalization in a tangible, stored form is already required. Thus, digital media transcend the distinction between internal and external. They can do so, because both internalized and externalized processes mediate between physical and mental processes. Thereby, they also reveal the dogmatic assumption that speech is immaterial and unmediated or less material than externalized media articulations. This distinction is rooted in Cartesian dualism, while res cogitans in today's epistemologies is moved into res extensa, as argued in section 1, as a result 
of the study of brain processes, revealing that mental processes are embodied and situated in time and space, even if the content of the mind may be fiction, mere imagination, memories of the past, or ideas and phantasies of the future.

Insofar as the notion of mediatization includes all sorts of digital processes, it opens up for the inclusion of a growing list of new trajectories, not simply because digital media are already incorporated in existing institutional frames (e.g. religion, education, home banking, media for the public, etc.), but also due to the innovation of new - digital - communicational features, genres, strategies, and eventually new societal fields, as there are no areas left that can remain permanently untouched by digitization. Still, digitization makes a difference both to nondigital phenomena and different kinds, strategies, and genres of digitization.

This is not to say that everything will be made digital. First, it is most likely that, in many cases, people will prefer non-digital interactions. Second, digital processes can never be made exclusively digital. They exist only as distinctions within a continuous physical universe. Embodiment matters for machines as for humans. There will always be some degree of materialization and anchoring in time and space in the form of a device and an interface allowing humans to make sense of the processes.

So far, it seems that digitization should be seen as a particular mode of mediatization or rather a set of particular modes of mediatization. These modes will always share the use of the binary alphabet, allowing the blending of expressions and genres as well as of platforms, while search, both on the algorithmic level of syntax and on the semantic, interfacial level of human experience and meaning, occurs in different modes and still evolving genres. As previously argued, they will also always deploy different forms of hypertextual, interactive, and multimodal means of expression.

The inclusion of all sorts of digital materials does not settle the issue of how mediatization relates to digitization. While mediatization is a broader notion than digitization, because it includes non-digital media, digitization is still a broader notion than the concepts of mediatization developed so far, because digitization includes not only digital materials, but also the coexistence of digital materials, digital media, and digital search facilities. The coexistence of these is unique, insofar as the relation between the material, the search method, and the media is variable. There is always a layer of software in between the tangible device and the genres and messages. This layer can both be used to define (and vary) the functional architecture of the device and to make the device responsive to the content of individual messages. None of this can take place in analogue electronic media or print media. Whether ordinary language (spoken or written) could be said to allow for similar interrelations will remain an object of further analysis.

Consequently, the machinery itself can never be left out as an invariant precondition for digital communication. Traditional "Newtonian" machines, however complex they are, can be defined as based on an intended repetitive functional 
architecture built into a physical, fixed form. Furthermore, the materials processed were not meant to interfere with the modus operandi of the machine, as it would disturb the processing. The images on the television screen should not change the functioning of the screen. Digital media are also mechanical devices, but they differ from "Newtonian machines", because the functional architecture can be defined in the form of organized physical energy, delivered as editable software. Thus, digital media enter more directly into the genres and content of communication than former media. As a consequence, the notion "media" is often both used for software applications (such as social media for instance) and for the devices in which they are implemented alongside other applications. Digital media are, in this respect, less able than older media to be transparent when used. They draw more attention to themselves than radio and television. To use the terms of Meyrowitz (1993), the functional architecture of digital media enters into the grammar of communication and not simply into the settings and channels.

\section{Medium theory revisited}

Within media and communication studies, medium theory is routinely criticized en bloc for being deterministic or dogmatic. The criticism may be directed towards the strong ideologies of McLuhan and others, who try to establish a very close relation between a particular medium and a general worldview, or it may be directed towards particular concepts like the notion of "bias" or, as is the case in Hepp, it may be argued that medium theory "leaves the impression of being an inadequate approach to the description of media culture, precisely because it reduces this media culture to that of one dominant media culture. But this is too simplistic: cultures moulded by media are much too contradictory to be reduced to any one dominating medium" (2013: 16).

This may be true, but it depends very much on what is meant by "dominating" and by "moulded". It also depends on the choice of sources. The criticism, for instance, does not fit well with Walther Ong and his analyses of the intricate relations between speech, writing, printing, and analogue electronic media, as expressed, for instance, in the notion of a secondary orality which denotes an "electronically mediated" oral form presupposing both writing and print (Ong 1983: 136). Likewise Meyrowitz (1985) repeatedly stresses that literacy remains important, and they both subscribe to the idea that old media are seldom replaced by new media. See also Meyrowitz (1994) for a less simplistic description of first and second generation medium theory. Even if medium theory in some interpretations reduces media culture to one dominant medium and culture, it is not necessarily an intrinsic part of the approach.

Furthermore, the idea of dominant media does not necessarily imply a reduction of media cultures, but it does imply the existence of relations between media, 
the complexity of which is a matter of empirical study. For Altheide and Snow there is no doubt that "every historical epoch is marked by the dominance of some media over others" (1979: 11). Today it would be difficult to find a medium that is not affected in a variety of ways by our usages of digital media. The issue is rather how such relations between media develop.

There are plenty of theories of the relations between media, including replacement theories (new media replace old media), theories of extension, different theories of convergence, theories of media evolution (both linear like Schulz [2004] and theories of increasing complexity), and finally theories of coevolution; see Finnemann (2006) for an overview. These and other theories also deviate in what they claim to be significant characteristics of the various media. There are also many empirically oriented cross-media and communication studies to consider.

Hepp is correct, however, in arguing that McLuhan, Meyrowitz and Ong and others include analogue and digital electronic media in one overarching concept of electronic media, but there is a huge amount of literature that clearly distinguishes between analogue and digital electronic media, focusing on the particular biases and affordances of digital media as markedly different from those of analogue electronic media. For examples see Zuboff 1988; Bolter 1991; Landow 1992; Lanham 1993; Poster 1995; Levinson 1997; Castells 1996-1998; Deibert 1997; Finnemann 1999a, 2011; Benkler 2006; Baron 2008; Cardoso 2008.

Thus, it seems more preferable to consider medium theory part of a series of attempts to reflect the specificity of certain media, whether denoted as biases of media (Innis [1951] 1977), as enabling and disabling capacities of media (Pool 1990), or as affordances in the tradition of J. J. Gibson (1979).

While biases refer to properties of a particular medium, affordances refer to a particular relation between an organism and the surroundings. The concept has been transferred to human computer interaction and media and communication studies by Norman (1998) and Hutchby (2001) and others, referring to features that "invite" media users to engage in certain actions rather than others. While biases are more common in macroanalyses, affordances seem more popular in microlevel studies of particular media usages. A main difference, though often ignored, is whether the properties referred to are considered the properties of a medium, a bias, or refer to a relation between a medium and a particular kind of usage, an affordance anchored in particular properties of both.

Refuting medium theory approaches, but nevertheless asking for reflections of the specificities of media, Hepp suggests the notion of a "moulding force of media", which "reflects that media are at the same time an institutionalization as well as a reification of communication" (2012: 24), thus also including a loosely identified power issue, which may explain why the moulding force cannot "be seen beyond its context." It is not completely clear, however, how the notion of a moulding force differs from the established notion of affordances. If there is a difference, it seems to be that affordances are anchored in a relation between an 
organism and the surroundings, while the moulding force seems to be fully defined by and absorbed into the context in which it is identified. But if so, one might ask why the moulding force is not merely a part of the context, rather than "a force of the medium" (Hepp 2013: 60)?

It is not clear yet what the notion of a moulding force might add to the understanding of media and mediatization, but on the basis of medium theory approaches and other contributions it is possible to identify spatiotemporal, material, perceptual, and semiotic criteria characterizing particular media, though it will be necessary to include the whole matrix of media, as does for instance Ong (1983), when identifying the characteristics of each. It will also be necessary to distinguish between historical time/space relations related to the media generally available to society at large and the time/space scales of particular communicational acts.

A main question today is how these notions are affected by the advent of digital media, as it is possible to digitize all former media, if we so want. Thus, all the characteristics - biases and affordances - of the former media that were assumed to be stable become variable and editable in the new medium. The fixed text - formerly written, typed, or printed - becomes dynamic and hypertextual. The moving images as well as dynamic speech become storable in the very moment of digitization - even if they are redistributed in streamed formats, which cannot be stored. The flow television, formerly defined by the institutionalization of the mass media, now becomes an option on a par with other options for deciding when to see what on which screen. This is, of course, an option on the level of institutionalization, as it presupposes an open Internet, rather than proprietary systems, such as French Minitel in the 1980s or America Online (AOL) in the USA in the 1990s. The time/space characteristics of the 5 major media epochs is presented in Finnemann (2011).

As mentioned in the previous section one of the crucial dimensions of this change can be described as a transition of a range of media characteristics from what Meyrowitz (1993) defined as the settings of the medium, referring to the relatively stable parts of a media landscape, to the grammar of the medium, referring to the set of variables which can be used in the articulation of individual messages in a given medium.

The grammar of a medium equals linguistic grammar, as it specifies an array of rules and redundancy structures allowing the composition of an infinite number of different messages. However, the grammars of modern media, at the same time, differ from the grammar of both written and spoken language, as modern media come with an externalized and institutionalized grammar separate from the human memory. What a grammar does is primarily to describe possible rule-based or redundant patterns for articulation of meanings; in this respect, it will always transcend actual use, as do the linguistic grammars of our mother tongues. There is an infinite array of possible sentences still left to be articulated in the future. 
Like writing, print, radio, and television, digital media also open up for new trajectories marked as different from those opened by the former media. Regardless of whether this is progress or not, it is an empirical fact.

For digital media such new trajectories are opened both due to the navigation-, browse-, and search facilities and due to the hypertextual, interactive, and multimodal potentials of computers. All digital expressions can be related to these dimensions in one way or another.

For the Internet of today, based on a globalized set of standardized protocols, such as the TCP/IP, and generally open for new entry points, we can add three more grammatical dimensions to the new trajectories. These are the seamless variations on the scales of a) public, semi-public, semi-private, and private communication, b) local, national, and transnational reach, and c) the choice of communication partner, both on the side of senders and receivers (Finnemann 2005).

Any digital expression utilizes these dimensions, and its particular utilization of these may be analysed; some are defined on the level of the software used, some are defined on the level of sociocultural selection and institutionalization, and some are defined by the individual users according to their individual purpose and skills.

In the end, all these dimensions are anchored in the fundamental structure of digital media which, contrary to formerly known mechanical devices, are characterized by a variable functional architecture that always represents some search method for combining and presenting data in a perceptible form, allowing people to make sense of it.

Insofar as new media do not replace old media, there is still a need for a concept of mediatization that refers to the overall set of available media, the matrix, and which cannot be reduced to the forms of mediatization implied by the use of any single medium, however dominant it may turn out to be in a long-term perspective. To include digital media, media and communication studies should provide itself with a concept of digital media, and to do so, it has been argued, it is also necessary to redefine the concepts of media and mediatization.

\section{Acknowledgements}

The author would like to acknowledge the contribution of the COST Action IS1004 WEBDATANET: web-based data collection, methodological challenges, solutions and implementations. www.webdatanet.eu 


\section{References}

Altheide, David L. and Robert P. Snow. 1979. Media Logic. Beverly Hills, CA: Sage.

Baron, Naomi S. 2008. Always On. Language in an Online and Mobile World. Oxford: Oxford University Press.

Benkler, Yochai. 2006. The Wealth of Networks. How Social Production Transforms Markets and Freedom. New Haven, CT: Yale University Press.

Bolter, Jay D. 1991. Writing Space. The Computer, Hypertext, and the History of Writing. Mahwah, New Jersey: Lawrence Earlbaum.

Brügger, Niels and Niels Ole Finnemann. 2013. The web and digital humanities. Theoretical and methodological concerns. Journal of Broadcasting \& Electronic Media. DOI:10.1080/ 08838151.2012 .761699

Buss, David M., Martie G. Haselton, Todd K. Shackelford, April L. Bleske and Jerome C. Wakefield. 1998. Adaptations, exaptations, and spandrels. American Psychologist 53(5): 533-548. http://sscnet.ucla.edu/comm/haselton/webdocs/spandrels.html

Cardoso, Gustavo. 2008. From mass to networked communication: Communicational models and the information society. International Journal of Communication 2: 587-630.

Castells, Manuel. 1996-1998. The Information Age I-III. London: Blackwell Publishing Ltd.

Castells, Manuel. 2009. Communication Power. New York: Oxford University Press.

Dahlgren, Peter and Claudia Alvares. 2012. Political Participation in an Age of Mediatization: Toward A New Research Agenda. ESF Forward Look 'Media studies: new media and new literacies'. Draft (received August 2012).

Deibert, Ronald. 1997. Parchment, Printing, and Hypermedia. Communication in World Order Transformation. New York: Columbia University Press.

Elias, Norbert. 1991. The Symbol Theory. London: Sage.

Finnemann, Niels Ole. [1994] 1999a. Thought, Sign and Machine - The Computer Reconsidered. E-text Revised English translation from Danish by G. Puckering. Tanke, Sprog og Maskine. 1994. Copenhagen: Akademisk Forlag. http://hum.au.dk/ckulturf/pages/publications/nof/ tsm/abstract.html

Finnemann, Niels Ole. 1999b. Modernity modernized. In: Paul A. Mayer (ed.), Computer Media and Communication - A Reader, 141-160. Oxford: Oxford University Press.

Finnemann, Niels Ole. 2005. The cultural grammar of the internet. In: K. B. Jensen (ed.), Interface://Culture - The World Wide Web as Political Resource and Aesthetic Form, 52-71. Copenhagen: Samfundslitteratur/Nordicom.

Finnemann, Niels Ole. 2006. Public space and the coevolution of digital and digitized media. Tidsskriftet Politik 9(2): 64-74.

Finnemann, Niels Ole. 2011. Mediatization theory and digital media. Communications 36: 67-89. DOI 10.1515/COMM.2011.004.

Finnemann, Niels Ole, Per Jauert, Jakob Linaa Jensen, Karen Klitgaard Povlsen and Anne Scott Sørensen. 2012. The Media Menus of Danish Internet Users, Web edition: http:// changingborders.au.dk/wp-content/uploads/2012/05/The-Media-Menus-of-Danish-InternetUsers-2009.pdf. Survey data: Dansk Data Arkiv: DDA-26276: Offentlighedens nye grænseflader, 2009. Funded by The Danish National Research Council: Humanities. Grant No: 09-063951.

Finnemann, Niels Ole. 2014. Research libraries and the Internet. Journal of Documentation 70(2): 5-32 Special Issue. http://emeraldinsight.com/journals.htm?issn=0022-0418\&volume=70\& issue $=2$ (Accessed January 9. 2014)

Foot, Kirsten A. and Steven M. Schneider. 2006. Web Campaigning. Cambridge, Mass: MIT Press. Gibson, James J. 1979. The Ecological Approach to Visual Perception. Boston, MA: HoughtonMifflin. 
Guillory, John. 2010. Genesis of the media concept. Critical Inquiry 36: 321-362.

Gould, Steven J. and Elisabeth S. Vrba. 1982. Exaptation: A missing term in the science of form. Paleobiology 8: 4-15.

Gould, Steven J. 1991. Exaptation: A crucial tool for evolutionary psychology. Journal of Social Issues 47: 43-65.

Halavais, Alex. 2009. Search Engine Society. London: Polity Press.

Hallin, Daniel C., and Paolo Mancini. 2004. Comparing Media Systems. Cambridge, UK: Cambridge University Press.

Hepp, Andreas. 2012. Mediatization and the "molding force" of the media. Communications 37: 1-28. DOI 10.1515/commun-2012-00012.

Hepp, Andreas. 2013. Cultures of Mediatization. Cambridge, UK: Polity.

Hjarvard, Stig. 2008. The mediatization of society. A theory of the media as agents of social and cultural change. Nordicom Review 29(2): 105-134.

Hutchby, Ian. 2001. Technologies, texts, and affordances. Sociology 35(2): 441-456.

Innis, Harold. [1951] 1977. The Bias of Communication. Toronto: University of Toronto Press.

Krotz, Friedrich. 2007. The meta-processes of "mediatization" as a conceptual frame. Global Media and Communication 3(3): 256-260.

Krotz, Friedrich. 2009. Mediatization: A concept with which to grasp media and societal change. In: K. Lundby (ed.), Mediatization, Concepts, Changes, Consequences, 21-31. New York: Peter Lang.

Küng, Lucy, Robert G. Picard and Ruth Towse (eds.). 2008. The Internet and the Mass Media. London: Sage.

Landow, Georg P. 1992. Hypertext: The Convergence of Contemporary Critical Theory and Technology. Baltimore: The Johns Hopkins University Press.

Lanham, Richard A. 1993. The Electronic Word. Democracy, Technology, and the Arts. Chicago: University of Chicago Press.

Levinson, Paul. 1997. The Soft Edge. A Natural History and Further of the Information Revolution. London: Routledge.

Lundby, Knut. 2009. Media logic: Looking for social interaction. In: K. Lundby (ed.), Mediatization, Concepts, Changes, Consequences, 101-121. New York: Peter Lang.

Meyrowitz, Joshua. 1985. No Sense of Place: The Impact of Electronic Media on Social Behavior. New York: Oxford University Press.

Meyrowitz, Joshua. 1993. Images of media: Hidden ferment - and harmony - in the field. Journal of Communication 43(3): 55-66.

Meyrowitz, Joshua. 1994. Medium theory. In: D. Crowley and D. Mitchell (eds.), Communication Theory Today, 50-77. London: Polity Press.

Norman, Donald A. 1998. The Design of Everyday Things. Cambridge, MA: MIT Press.

Oxford English Dictionary. 2012. Oxford. http://oed.com/ (Accessed December 20, 2012).

Ong, Walther J. 1983. Orality and Literacy. The Technologizing of the Word. London and New York: Routledge.

Peters, John Durham. 1999. Speaking into the Air. A History of the Idea of Communication. Chicago: University of Chicago Press.

Pool, Ithiel de Sola. 1990. Technologies without Boundaries. On Telecommunications in a Global Age. Cambridge, MA: Harvard University Press.

Poster, Mark. 1995. The Second Media Age. Cambridge, UK: Polity Press.

Reips, Ulf-Dietrich. 2008. How internet-mediated research changes science. In: Azy Barak (ed.), Psychological Aspects of Cyberspace: Theory, Research, Applications, 268-294. Cambridge, UK: Cambridge University Press.

Riepl, Wolfgang. 1913. Das Nachrichtenwesen des Altertums mit besonderer Rücksicht auf die Römer [The News Communications of the Ancient World with Special Reference to the Romans]. Leipzig: Teubner. 
Rothenbuhler, Eric W. 2009. Continuities: communicative form and institutionalization. In: Knut Lundby (ed.), Mediatization, Concepts, Changes, Consequences, 277-292. New York: Peter Lang.

Shannon, Claude E. and Warren Weawer. [1949] 1969. The Mathematical Theory of Communication. Urbana: University of Illinois Press.

Schulz, Winfried. 2004. Reconstructing mediatization as an analytical concept. European Journal of Communication 19(1): 87-101.

Strömbäck, Jesper. 2008. Four phases of mediatization: An analysis of the mediatization of politics. The International Journal of Press/Politics 13(3): 228-246.

Wurff, Richard van der and Edmund Laub (eds.). 2005. Print and Online Newspapers in 16 European Countries. Amsterdam: Het Spinhuis.

Zuboff, Shoshana. 1988. In the Age of the Smart Machine: The Future of Work and Power. New York: Basic Books. 
